\title{
Physiological and molecular plant pathology by H.N. Gaur
}

\section{Scientific publishers (India), Jan 2018, p 540. ISBN: 97938652331 , price: INR 3650}

\section{D. Mayee ${ }^{1,2}$}

Published online: 27 July 2018

(c) Indian Phytopathological Society 2018

All the Plant Pathologists shall agree after reading the recent volume "Physiological and molecular plant pathology written by Dr H.N. Gaur, Emeritus Professor, Maharana Pratap University of Agriculture and Technology, Udaipur, that the book is an excellent addition to the book shelf of Plant Pathology. In fact Dr. M.S. Swaminathan, the father of Green Revolution in India, very aptly summed up the philosophy of the book that the book has both the science and art of Plant Pathology as elaborated by Horsfall and Cowling in their first volume of the series of five volumes of PLANT DISEASE, that understanding the disease is science and practicing the management of disease is an art. Today the tremendous advances in biotechnology, molecular biology, genomics, the IPR regimes and patents have become part of biological sciences and therefore, Plant Pathology is not restricted to science and art but an element of commerce has been introduced due to commercialization of patented technologies.

The book traces the history of the subject but with a difference which has relevance to the current advances. The peculiar process of pathogenesis of crown gall diseases caused by the bacterium, Agrobacteruim tumefaciens discovered some time in 1890 has now revolutionized the science of genetic engineering and this bacteria is considered as the natural genetic engineer of plants. The author has redefined the original concepts of pathogen, pathogenicity, pathogenesis, parasitism and so on; in the light of new knowledge of molecular biology. The chapters are arranged in a very lucid manner and one goes through it like a step by step learning

C. D. Mayee

charumayee@sabc.asia

1 Agricultural Scientists Recruitment Board, Indian Council of Agricultural Research, New Delhi, India

2 South Asia Biotech Centre, New Delhi, India of Plant Pathology. Firstly, the book narrates as to how the pathogen invade the host by breaking the barriers. They are known to use several weapons in their armour such as; toxins, enzymes, direct penetrations and so on. This is followed by the mechanisms invoked by host and thus goes the fight all controlled by again factors like environment, space and time. Ultimately, disease is an outcome of the battle won by pathogen and health is the product of resistance shown by host. The process of infection commences with right earnest for survival of the organisms but then several external factors determine the ultimate signs, symptoms and damage.

Along with the chapters on physiological and molecular bases of host-pathogen interactions, the author added some very useful information on plant biotechnology, bioinformatics, sociological and ethical angles of the new discoveries, which are essential to be read by all Plant Pathologists because such information at one place is difficult to be found. I strongly recommend the book to all the teachers of Plant Pathology whose concepts once get cleared can be useful in teaching even at undergraduate level. It should be part of the text book for the post graduate students of the subject, may be they are pursuing fungal, bacterial, viral, nematode or abiotic pathology .I find that even some of the narrations on the recent advances of biotechnology, bioinformatics could also be useful for the students of Plant Protection sciences. I congratulate the author for bringing a very comprehensive volume on physiological and molecular aspects of Plant Pathology. 